\title{
INVESTASI SYARIAH DAN PERTUMBUHAN EKONOMI: OPTIMASI PERAN SUKUK SEBAGAI PENUNJANG PEMBANGUNAN EKONOMI NASIONAL
}

\section{Reza Henning Wijaya**}

${ }^{1}$ Program Studi Akuntansi, Universitas Tidari,rezawijaya102@gmail.com

\begin{abstract}
Massive movement of sharia things in the world, it given impact to all of countries, no exception Indonesia. This descriptive research aims to depict sharia investement especially sukuk able to contribute in national economy development. This research method is qualitative with library research. Sukuk able to cover deficit Indonesia APBN to support infrastructure developing, built labor insentive, and developing region potency. But Indonesia still needs some regulations and policies to optimize role of sukuk in national economy development itself.
\end{abstract}

Keywords: Sukuk, National Economy Development, APBN.

\begin{abstract}
ABSTRAK
Masifnya pergerakan syariah di dunia, memberikan pengaruh kepada semua negara tidak terkecuali Indonesia. penelitian deskritif ini bertujuan untuk menggambarkan investasi syariah khususnya sukuk mampu untuk berkonstribusi pada pembangunan ekonomi nasional. Penelitian ini menggunakan metode kualitatif dengan library research. Sukuk mampu untuk menahan defisit APBN Indonesia untuk mendukung pembangunan infrastruktur, sektor padat karya, dan mengembangkan potensi daerah. Namun Indonesia masih membutuhkan beberapa regulasi dan kebijakan untuk mengoptimalkan peran sukuk dalam pembangunan ekonomi.
\end{abstract}

Kata Kunci: Sukuk, Pembangunan Ekonomi Nasional, APBN

\section{PENDAHULUAN}

Sukuk merupakan salah satu instrumen investasi syariah yang memiliki potensi agar dikembangkan sebagai pendorong pembangunan ekonomi nasional. Indonesia merupakan negara dengan umat muslim terbesar di dunia berdasarkan data dari religious future (2019)

\footnotetext{
**Penulis Korespondensi
} 
penduduk muslim di Indonesia akan mencapai 229,62 juta jiwa di tahun 2020. Senada dengan potensi tersebut maka pengembangan instrumen kuangan syariah di Indonesia memiliki prospek yang cerah salah satunya sukuk. Menurut Beik (2011) secara sederhana sukuk atau obligasi syariah diartikan sebagai surat berharga jangka panjang yang dikeluarkan emiten, yang mewajibkan emiten membagikan hasil berupa margin kepada pemegang. Akad-akad pada sukuk ada yang berbasis bagihasil seperti musyarakah dan mudharabah, berbasis jual beli seperti istishna, salam, dan murabahah, sampai sewa menyewa seperti ijarah. Oleh karena itu hal-hal tersebutlah yang membuat sukuk berbeda dengan obligasi konvensional yang berbasis pada bunga sebagai marjinnya.

Merujuk pada data Badan Pusat Statistik (BPS) menunjukan bahwa pertumbuhan ekonomi di Indonesia masih menunjukan kurva berbentuk huruf W, yang mengartikan bahwa Indonesia belum stabil dalam pertumbuhan ekonomi itu sendiri. Saat ini, Indonesia dan semua negara di dunia menghadapi resiko resesi yang mengancam berbagai sektor di dalamnya yang diakibatkan adanya pandemi covid-19. Adanya pandemi covid-19, dapat berakibat pada defisitnya APBN maka peningkatan sektor rill diharapkan mampu meningkatkan pangsa pasar salah satunya dengan instrumen syariah yang berprinsip dengan bagi hasil. Menurut Beik (2011) peran sukuk negara dalam pembangunan adalah sebagai alat meringankan defisit APBN yang mampu digunakan pada pembangunan sektor rill. Hastuti (2017) sukuk retail dapat menjadi pionir dalam hal investasi syariah khsusnya di bidang sukuk seperti Malaysia. Masifnya perkembangan instrumen syariah di Indonesia seharusnya konsep keuangan syariah yang diterima di Indonesia dapat membuat sukuk mengalami perkembangan yang pesat.

Pengembangan sukuk di Indonesia dapat mendorong pemerintah dalam meghadapi beberapa resiko yang berkenaan dengan likuiditas (Hastuti, 2017). Maka dibutuhkan pengelolaan instrumen syariah di Indonesia agar dapat meminimalkan resiko tersebut. Menurut Latifah (2020) penerbitan SBSN saat ini telah menjadikannya sebagai instrumen pembiayaan utama, selain instrumen pembiayaan sebelumnya yakni Surat Utang Negara dan pinjaman langsung. Oleh karena itu meskipun SBSN merupakan instrimen baru dalam pembayaran obligasi (sukuk) dengan demikian, SBSN telah menunjukan kemampuannya dalam membiayai defisit anggaran pemerintah.

Berkaca pada krisis keuangan atau moneter (Krismon) 1998 yang memberikan pengaruh signifikan dan masih terasa hingga saat ini efeknya seperti tingginya nilai suku bunga dan 
rendahnya nilai tukar rupiah. Hal ini salah satunya dikarenakan lemahnya pembangunan sektor rill dan hanya berpacu terhadap satu mata uang yakni US Dollar. Merujuk pada (Ramadayanti et al, 2017) dengan judul Peran Sukuk Negara dalam Pembiayaan Inrastruktur, menunjukan sektor konvensional cenderung bermain pada sektor finasial dibandingkan sektor rill yang menybabkan transaksi spekulatif berdasarkan nilai suku bunga. Pada hasil penelitian Ramadayanti et al (2017) di tahun 2017 terdapat enam sasaran infrastruktut dikembangkan antara lain: (1) Pembangunan jalan sepanjang $836 \mathrm{KM}$, (2) Pembangunan jembatan sepanjang 10.198 M, (3) Pembangunan 13 Bandara baru dan lanjutan, (4) Pembangunan dan pengembangan fasilitas pelabuhan, (5) Pembangunan jalur kereta api tahap I dan lanjutan sepanjang 710 KM spoor, dan (6) Pembangunan terminal penumpang lanjutan di 3 lokasi maka peningkatan pembiayaan infrastruktur berbasis sukuk mengalami peningkatan dan telah menunjukan sukuk menjadi instrumen penting dalam pembangunan sektor rill.

Konvergensi pengembangan sukuk di Indonesia secara bottom-up dan top-down bertujuan untuk menyelaraskan program-program pemerintah dan masyarakat dalam pembangunan ekonomi. Merujuk pada pernyataan Dirjen Pembiayaan Infrastuktur PUPR, Eko D. Heripoerwanto (2020) dalam Kusuma (2020) Indonesia membutuhkan kolaborasi pembiayaan untuk mengejar gap infrastruktur di Indonesia karenanya infrastruktur merupakan bagian penting kebutuhan masyarakat dalam peningkatan nilai konsumsi, akses lapangan kerja, kemakmuran nyata, dan stabilitas makro ekonomi. Namun demikian pembangunan infrastruktur di Indonesia masih mengalami ketertinggalan dengan negara-negara asia lainnya, merujuk pada standar World Economy Forum (WEF) standar pada negara maju berkisar pada angka 70\%, sedangkan Indonesia masih berada di angka 43\% terhadap Produk Domestrik Bruto (PDB). Saat ini, secara proporsi APBN Indonesia hanya memenuhi $30 \%$ dari pendanaan sehingga membutuhkan 70\% alternatif lain (Heripoerwanto, 2020) dalam Kusuma (2020).

Berdasarkan penelitian terdahulu mengenai investasi syariah yang ditulis oleh Peristiwo (2016) kehalalan terhadap imbal hasil yang diperoleh dari kegiatan investasi syariah akan menambah keyakinan investor untuk berinvestasi pada pasar modal syariah. Anik dan Prastiwi (2017) perkembangan sukuk saat ini harus dapat dimasifkan sebagai upaya peningkatan market share sukuk dengan membuat beberapa strategi dalam hal edukasi, komunikasi, pemasaran, dan pengembangan untuk mengakomodir percepatan dan pertumbuhan obligasi syariah/ sukuk. Kebermanfaatan sukuk dapat mendorong 
perkembangan pasar keuangan syariah untuk menciptakan branchmark di pasar keuangan syariah dan disversifikasi basis investor dalam mengembangkan instrumen investasi dan memanfaatkan dana-dana yang belum terjaring oleh sistem konvensional (Latifa, 2020). Fadlan (2010) perencanaan ini harus menetapkan struktur yang diperlukan pada pemenuhan kebutuhan ekonomi dan mengurangi ketidak seimbangan antara mikro dan makro ekonomi.

Perbedaan penelitian ini dengan penelitian sebelumnya terletak pada fokus penelitian. Penelitian ini berfokus pada peran sukuk dalam pembangunan ekonommi berkelanjutan di Indonesia. Maka adapun tujuan dari penelitian ini ialah untuk mengetahi lebih dalam bagaimana perkembangan sukuk sebagai instrumen investasi syariah serta peranannya pada pertumbuhan ekonomi berkelanjutan Indonesia.

\section{LITERATUR REVIEW}

\section{Sukuk}

Secara konsep, keuangan syariah di Indonesia sudah diterima dan dikembangkan yang mencakup perkembangan sukuk. Sukuk merupakan investasi syariah yang halal dan terbeas dari adanya praktik MAGHRIB (maysir, gharar, dan riba sesuai dengan firman Allah dalam AlQur'an Surat Al-Baqarah ayat 275 dan Al-Maidah ayat 1:

"Orang-orang yang makan (mengambil) riba tidak dapat berdiri melaikan seperti berdirinya orang yang kemasukan syaitan lantaran (tekanan) penyakit gila. Keadaan mereka demikian adalah disebebkan mereka berkata berpendapat,, sesungguhnya jual beli itu sama dengan riba. Padahal Allah telah menghalalkan jual beli dan mengharamkan riba. Orang-orang yang telah sampai kepadanya larangan dari Tuhannya, lalu terus berhenti (dari mengambil riba). Maka baginya apa yang telah diambilnya dahulu (sebelum datang larangan) dab urusannya (terserah) kepada Allah. Orang yang kembali mengambil riba. Maka orang itu adalah penghuni-penghuni neraka yang mereka kekal di dalamnya". (Q.S Al-Baqarah: 275).

“Hai orang-orang yang beriman penuhilah akad-akad itu....” (Q.S Al-Maidah: 1)

Sebagai salah satu instrumen investasi syariah, sukuk berasal dari bahasa arab yang berarti sak (tunggal) dan sukuk (jamak) yang memiliki pengartian serupa dengan sertifikat. Menurut Hastuti (2017) sukuk diartikan sertifikat aset yang dapat digunakannn untuk membiayai suatu pembangunan. Secara praktis sukuk didefinisikan bukti kepemilikan karena pada masa itu sukuk dipergunakan para pedagang sebagai dokumen yang menunjukan 
kewajiban keuangan yang ada karena aktivitas muamalah dan komersial lainnya (Beik, 2011). Berdasarkan Standar Syariah the Accounting and Auditing Organization for Islamic Finance Intitution (AAOIFI) N0.17 tentang sukuk investasi, sukuk didefinisikan sebagai sertifikat bernilai yang sama juga merupakan bukti atas kepemilikan yang tidak terbagi terhadap suatu aset baik hak manfaat serta jasa-jasa, atau kepemilikan proyek investasi tertentu.

Fatwa Dewan Pengawas Syariah (DSN) MUI Nomor: 32/ DSN-MUI/IX/2002 tentang obligasi syariah menjelaskan sukuk adalah suatu surat berharga jangka panjang berdasarkan prinsip syariah yang dikeluarkan emiten kepada pemegang obligasi syariah. Sukuk mewajibkan para emiten untuk membayar pendapatan kepada pemegang obligasi berupa bagi hasil serta membayarkan kembali dana obligasi pada saat jatuh tempo. Dasar hukum penerbitan sukuk adalah UU Nomor 19 Tahun 2008 tentang SBSN, dan Peraturan Kemenkeu Nomor 19 Tahun 2015 tentang penerbitan dan penjualan sukuk yang sebagaimana diubah dengan PMK Nomor 110 Tahun 2016 sukuk tabungan menggunakan akad wakalah yakni investment agency sukuk.

Pada perkembangannya sukuk terus menunjukan perannya dalam mendorong ekonomi umat, sejak dirilis pertamakali pada tahun 1990 jumlah sukuk secara global telah mencapai pada angka USD 199,18 Miliyar. Terlebih pada tahun 2009 sukuk mengalami peningkatan secara signifikan yang menjadikannya tren syariah. Hal ini dipengaruhi karena sukuk memiliki sisi konektivitas dengan sektor rill yang secara otomatis sukuk memiliki direct link dengan akadakad keuangan syariah lainnya, perbedaannya dengan sukuk konvensional ialah sukuk konvensional belum tentu memiliki keterbuhungan dengan sektor rill tersebut (Beik, 2011).

\section{Pembangunan Ekonomi Nasional}

Al-Buraey (1986) dalam Fadlan (2010) memandang pembangunan dalam dimensi Islam dengan delapan cara perubahan yaitu terencana, indoktrinasi, koersif, teknokratis, interaksional, sosialisasi, emulatif, dan alamiah. Fadlan (2010) di Indonesia, yang paling tepat ialah aspek perubahan terencana sebab kekuatan ekonomi Indonesia dewasa ini masih didukung oleh sistem konvensional. Konsep pembangunan dalam Islam menurut beberapa literatur merujuk pada produktivitas ekonomi secara keseluruhan yang diikuti kesejahteraan masyarakatnya. Ahmed (1976) Islam sangat memperhatikan masalah pembangunan ekonomi negara dan tetap menempatkannya pada persoalan paling penting karena berkaitan pembangunan umat. Maka fungsi Islam ialah membimbing manusia pada jalur yang tepat. 
Kaitannya dengan sukuk, Latifa (2017) pemerintah memiliki tujuan atas penerbitan sukuk negara ialah dalam hal pembiayaan APBN, SBSN dapat dijadikan pembiayaan negara dalam APBN yang berkaitan dengan pembangunan ekonomi. Menurut Beik (2011) dan Ashari dan Saptana (2005) hal tersebut berkaitan dengan sektor padat karya untuk mengoptimalkan orientasi daerah, pembangunan infrastruktur seperti transportasi, telekomunikasi, dan lain sebagainya. Mengingat ketertinggalan infrastruktur di Indonesia, secara ekonomi menciptakan multiplayer effect yang dapat dihasilkan secara inklusif. Definisi pembangunan inklusif menurut International Disability and Development Consorium (IDDC) merupakan pembangunan yang dapat dirasakan semua orang tanpa terkecuali dan dalam prosesnya pembangunan tersebut dilakukan secara aktif sampai manfaatnya terasa secara luas. Oleh karena itu sukuk dikeluarkan pemerintah sebagai penyeimbang dari kekayaan neraca keuangan baik pemerintah, perusahaan, bank, dan lembaga keuangan lainnya yang berbentuk entitas yang memobilisasi dana masyarakat (Umam, 2013).

\section{Indonesia dan Sukuk: Peluang dan Tantangan}

Indonesia merupakan negara muslim terbesar di dunia sesudahIndia dan Pakistan. Senada dengan hal tersebut Global Islamic Finance Report pada tahun 2018 melaporkan bahwa Indonesia memiliki potensi luar biasa untuk mengembangkan sistem keuangan syariah. Menurut Damhuri (2018) dalam Latifa (2020) selain potensi tersebut, bonus demografi, kelas menengah yang besar, penetrasi keuangan syariah yang masih relatif rendah menjadi faktor determinan berkembangnya sistem syariah pada perekonomia Indonesia. Sunarsih (2008) dapat dipastikan produk-produk syariah di Indonesia termasuk sukuk akan laris di pasaran seperti halnya negara-negara Timur Tengah. Baik di bank nasional atau internasional instrumen sukuk tumbuh pesar seiring dengan perkembangan keuangan lainnya.

Pada tahun 2002 sukuk petamakali mncul di Indonesia yang diprakasai oleh PT Indonesian Satelite Corporation (Indosat) dengan nama obligasi syariah. Kala itu, penamaan obligasi syariah dengan sukuk hanya populer pada bidang-bidang akademisi. Namun sejak dikelaurkannya peraturan Badan Pengawas Pasar Modal dan Lembaga Keuangan (BAPEPAM) No.IX.13.A tentang penerbitan efek syariah dan ditetapkannya UU No.19/ 2008 tentang surat berharga syariah negara istilah sukuk mulai populer dan sering digunakan. 
Menurut Fatah (2011) keberadaan sukuk di Indonesia dapat memperkuat kondisi ekonomi dan menahan buble ekonomi karena akan memperbanuak portfolio dengan mata uang asing selain dolar. Sukuk dapat memberikan sensasi investasi baru karena dapat dimanfaatkan unruk membangn ekonomi dan diserap habis oleh pasar. Berbanding lurus dengan peluang, tantangan sukuk khususnya di Indonesia dapat terlihat dari berbagai aspek, utama diantaranya pemahaman masyarakat akan keberadaan sukuk. Telah menjadi permasalahan klasik dan bukan terjadi pada instrumen sukuk saja melainkan instrumen-instrumen syariah lainnya seperti reksadana, asuransi, saham, dan lain sebagainya (Fatah, 2011). Hal lainnya mengenai standarisasi fatwa mengenai struktur instrumen syariah di masing-masing negara karena tidak semua negara dengan mayoritas Islam beracuan pada AAOIFI (Mohamad et al, 2012) dan (Lahsasna dan Lin, 2012).

\section{METODE}

Metode penelitian yang digunakan oleh penulis ialah kualitatif dengan jenis library research, dimana permasalahan penelitian dilandasi pada data-data yang berasal dari berbagai literatur. Moloeg (2007) penelitian kualtatif bermakna untuk memahami fenomena tentang apa dan bagaimana fenomena tersebut terjadi ditinjau dari subjek penelitian. Segala hal yang berkenaan dengan historik dan deskripsi dalam bentuk kata-kata dan bahasa dalam konteks khusus yang alamiah diteliti untuk mendapatkan hasil penelitian. Identifikasi data-data pada penelitian ini dilalui dengan prosedur berikut: (1) Merumuskan tujuan secara spesifik terkait hal-hal yang ingin dicapai. (2) Mengidentifikasi istilah-istilah penting yang harus dijelaskan secara mendalam seperti sukuk. (3) Mengkhususkan unit analisis, yakni pertumbuhan ekonomi nasional. (4) Mencari data dan sumber yang relevan. (5) Membangun hubungan rasionalitas dan konseptual agar menghasilkan hasil yang berkenaan dengan tujuan penelitian. Sumber penelitian ini ialah data-data sekunder yang bersumber pada studi pustaka, literatur, dan dokumen-dokumen yang berkenaan dengan topik atau penelitian yang ditulis.

\section{HASIL DAN PEMBAHASAN}

Merujuk Pada Beik (2011) menilik secara lebih dalam, sukuk berorientasi pada SBSN dalam menangangi defisit APBN. Hasil penelitian tersebut didukung penelitian yang dikemukakan Mitsaliyandito et al (2017) bahwa sukuk telah mendukung pembangunan 
ekonomi nasional yang tidak hanya berkontribusi pada sektor privat, namun juga berpengaruh terhadap PDB negara. Optimasi peran sukuk dalam pembangunan ekonomi nasional akan membawa banyak pengaruh positif yang hampir pasti. Senada dengan Mitsaliyandito et al (2017) pemerintah saat ini sedang berkomitmen membangun infrastrukrur. Maka peluang untuk mengembangkan instrument investasi syariah di Indonesia, khususnya sukuk dengan alasan pembangunan patut diprioritaskan.

Masifnya perkembangan sukuk di Indonesia bilamana dibandingkan dengan Malaysia, Malaysia lebih unggul dibandingkan Indonesia. Pengembangan keuangan syariah di Malaysia telah menjadikannya sebagai pasar sukuk terbesar. Jakarsih dan Rusydiana (2009) bahkan pada tahun 2007 hampir 70\% dari total emisi sukuk di dunia diterbitkan di Malaysia. Pengembangan sukuk dan instrumen investasi syariah sebaiknya juga memperhatikan aspek kualitas disamping kuantitas. Adanya variasi sukuk yang inovatif dan kompetitif dapat menarik minat investor berinvestasi (Mosaid dan Boutti, 2014). Terdapat beberapa tinjauan yang dapat diperharikan di Indonesia dalam megoptimalkan peran sukuk pada pembangunan ekonomi nasional antara lain:

1. Pengembangan struktur dengan inovatif

Struktur sukuk di Malaysia disesuaikan dalam rangka membidik target pasar yang lebih spesifik. Sehingga sukuk yang ditawarkan sesuai dengan keadaan para investor seperti perubahan basis. Misalnya dari struktur sukuk berbasis hutang dengan jual beli (murabahah) menjadi ijarah atau sewa-menyewa, bagi hasil atau musyarakah, kontrak kerja atau istishna, dan sukuk campuran.

2. Perlakuan hukum yang jelas dan pasti

Perlakuan hukukm dibuat sejelas mungkin (meminimalkan peraturan atau hukum yang bias). Langkah ini guna memberi kepastian hukum bagi lembaga keuangan syariah untuk berinvestasi khususnya pada instrumen sukuk. Misalnya dengan prinsip kehati-hatian dalam berinvestasi sukuk pada peraturan permodalan dapat dicapai melalu adopsi capital adequacy standard yang dikeluarkan oleh IFBS.

3. Berfokus terhadap sistem pengembangan keuangan islam secara komperhensif

Menurut Jakarsih dan Rusydiana (2009) pada hal ini dapat mengadopsi strategi yang digunakan Malaysia penciptaan lingkungan yang efektif bagi penerbitan sukuk yakni dengan membuat peraturan yang memfasilitasi bagi penerbitan sukuk, insentif 
dalam aktivitas investasi, competitive pricing, dan kerangkakerja dan hukum syariah yang jelas di negara tersebut.

Sesuai dengan komitmen pemerintah untuk memperbaiki dan mengembangkan infrastruktur di Indonesi akan bertambah luas ruang fiskal APBN dengan terbitnya seri sukuk negara. Penambahan ruang ini dapat ditariknya pos belana negara sebagian ke dalam pos pembiayaan. Maka di masa yang akan datang akan ada banya proyek pemerintah yang terbiayai baik dari pos belanja dan pembiayaan. Kemampuan SBSN juga mengartikan secara luas kepada masyarakat (padat karya) untuk turut serta dalam pembangunan ekonomi nasional. Walaupun demikian, sukuk tetap membutuhkan underlying assets karena hal tersebut tergantung pada bagaimana produktivitas penggunaan dana itu sendiri Fathurahman dan Fitriati (2013). Adanya underlying assets akan berfungsi bagi para investor apabila emiten mengalami default atau gagal bayar. Underlying assets sukuk didasari pada proyek yang dilakukan oleh lembaga baik pemerintahan ataupun sektor private. Penyelesaian proyek pembangunan yang sesuai dengan waktua merupakan persyaratan secara syariah seperti yang sudah diatur di dalam struktur akad. Menurut Latifa (2020) dan Iskandar (2014) apabila terdapat keridaksesuaian dengan akad yang telah diatur maka harus dapat dicegah agar tidak menimbulan konsekuensi yang lebih rumit.

Seiring dengan perembangan zaman dan ekonomi, industri keuangan baik konvensional dan syariah memengaruhi masyarakat secara perlahan terkait pentingnya investasi. Dewasa ini, masyarakat secara luar diberikan kebebasan untuk memilih terkait basis apa yang dipilihnya baik konvensional ataupun syariah. Setiap orang memiliki dorongan untuk meningkatkan nilai aset yang dimilikinya sehingga dengan adanya SBSN sebagai salah satu media investasi dapat memberikan peluang bagi masyarakat untuk meningkatkan nilai asetnya. Pada praktiknya penerbitan SBSN akan memberikan tambahan investasi bagi pihak-pihak yang memiliki surplus dana. SBSN menjadi salah satu produk investasi yang menarik karena mendapatkan jaminan pembayaran berupa imbalan bahkan investasi pook oleh pemerintah. Maka dapat dikatakan SBSN merupakan investasi bebas resiko. Maka secara tidak langsung investasi ritel atau perorangan telah mendukung pembangunan ekonomi nasional yang juga diikuti pengembangan aset pribadi.

Tujuan pembangunan nasional ialah mendapatkan pertumbuhan ekonomi secara berkelanjutan dengan memiliki basis yang luas. Pembangunan ini seharusnya dilakukan di berbagai wilayah (Provinsi dan Kota/ Kabupaten) sehingga memunculkan efek berganda dalam 
praktiknya. Adapun skema yang dapat digambarkan melalui gambar 1. tentang pengaruh SBSN secara multiplayer effect berikut ini:

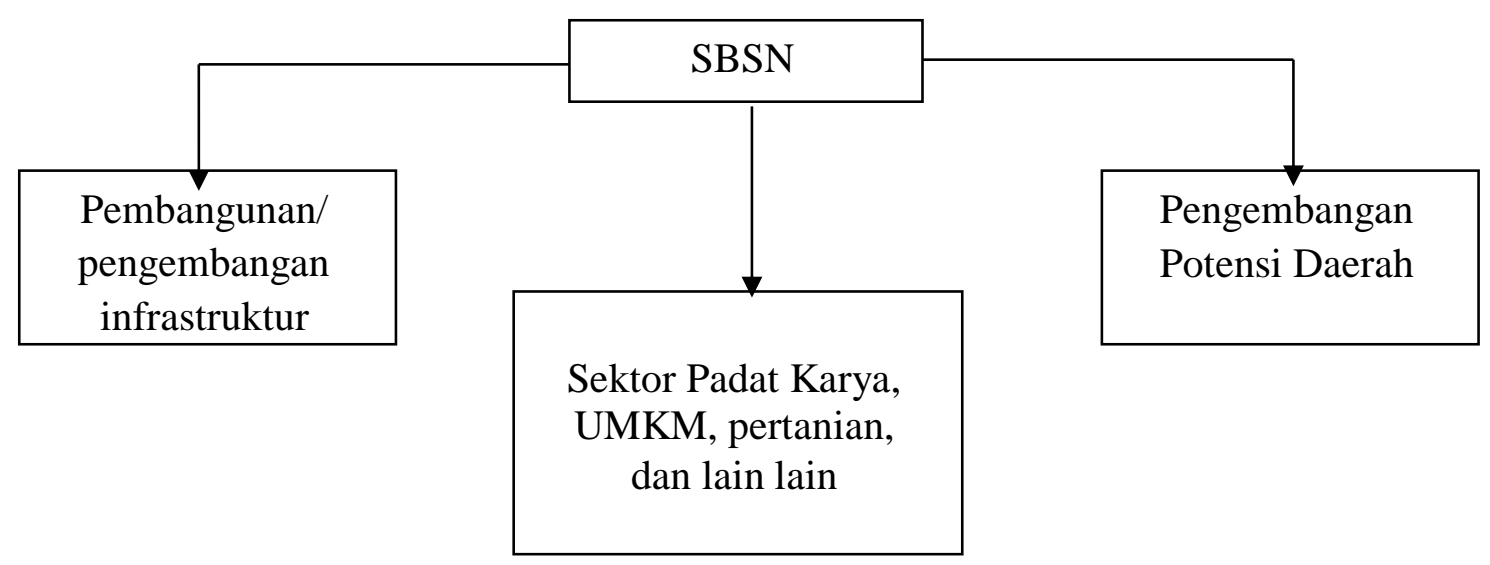

Gambar 1. Orientasi SBSN

Implementasi kebijakan sukuk di Indonesia diharapkan dapat dijalankan seperti gambar di atas. Maka dibutuhkan beberapa hal yang perlu diperhatikan agar tujuan falah dari pelaksanaan prinsip syariah dapat tercapai antara lain

1. Regulasi dan sinergisitas atar instansi berwenang

Keselarasan regulasi dan koordinasi antar instansi baik pemerintah dan sektor privat perlu dioptimalkan karena SBSN akan terbit dari berbagai sumber investasi pembangunan proyek. Maka diperlukan penguatan koordinasi antara menteri keuangan dan kementrian lainnya dan jika melibatkan daerah maka koordinasi antar pemerintah daerah (Beik, 2011).

2. Menajaga kesyariahan

Adanya masalah kepemilikan aset sukuk dan proteksi kapital harus ditinjau lebih dalam secara fikih. Hal ini bermula dari pernyataan Taqi Usmani pada tahun 2008 silam yang harus diperhatikan para pemangku kepentingan. Oleh karena itu singergisitas antara pelaku pasar, regulator, DSN MUUI dapat menjadi langkah tepat untuk menciptakan iklim yang kokoh dan terjamin kesyariahannya.

3. Peningkatan inovasi

Merujuk pada hasil penelitian Mohamad et al (2012) perkembangan sukuk di Malaysia cukup signifikan dan mempengaruhi beredarnya sukuk secara internasional. 
Hal ini didasari pada ragam instrumen sukuk dalam peningkatan kualitas dan masifnya inovasi, namun tetap menjaga kesyariahan sukuk itu sendiri. Maka peningkatan SDM yang memiliki kapasitas dan kapabilitas dalam penyusunan sukuk structuring. Beik (2011) SDM yang dibutuhkan harus dapat berfikir berbeda mengenai mindset obligasi secara konvensional dan secara syariah (surat utang negara konvensional).

4. Edukasi

Hal ini sangat fundamental karena kesadaran masyrakat masih relatif rendah mengenai produk-produk syariah. Anik dan Prastiwi (2017) memiliki strategi dengan memberikan praktuk pasar modal syariah di lingkungan kampus yang salah satunya untuk meningkatkan kesadaran akan produk syariah dan mempersiapkan SDM unggul. Terhadap masyarakat luas dapat dilakukan dengan eksalasi kampanye publik untuk mendorong minat masyarakat dalam berinvestasi secara syariah (Beik, 2011).

\section{SIMPULAN}

Penerbitan sukuk khususnya Sukuk Surat Berharga Syariah Negara (SBSN) sangat bermanfaat bagi pertumbuhan ekonomi Indonesia dalam meng-cover defisit APBN. Perkembangan sukuk di Indonesia menghadapi berbagai peluang dan tantangan yang menyertainya. Peluang, dikarenakan Indonesia merupakan negara muslim terbesar di dunia dan tantangan terkait minat dan kesadaran masyarakat pada investasi syariah. Sukuk akan menambah biaya APBN dalam pembangunan infrastruktur yang dibutuhkan oleh negara dengan memanfaatkan dana-dana masyarakat yang belum terhimpun oleh obligasi syariah. Oleh karena itu, harus adanya perbaikan berupa pembenahan sistem dan kebijakan terhdap sukuk itu sendiri. Serta mempersiapkan sumber daya manusia yang memiliki kapasitas dan kapabilitas dalam sukuk structuring.

\section{REFERENSI}

Anik, \& Prastiwi, I. E. (2017). Pengembangan Instrumen Sukuk Dalam Medukung Pembangunan Infratruktur. Jurnal Ilmiah Ekonomi Islam , 173-180.

Ashari, \& Saptana. (2005 ). Prospek Pembiayaan Syariah untuk Sektor Pertanian. Forum Penelitian Agro Ekonomi , 132-147.

Beik, S. I. (2011). Memperkan Peran Sukuk Negara dalam Pembangunan Ekonomi Indonesia. Jurnal Ekonomi Islam Al-Inaq , 65-72. 
Datuk, B. (2011). Sukuk Dimensi Baru Pembiayaan Pemerintah untuk Pertumbuhan. Jurnal Riset Akuntansi dan Bisnis , 13-24.

Dusuki, A. W., \& Mokhtar, S. (2010). Critical Appraisal of Shari'ah Issues on Ownership in Asset based Sukuk as Implemented in the Islamic Debt Market . International Research Paper, 10-21.

Fadlan. (2010). Konsep Pembangunan Ekonomi Berbasis Islam. Al-Hikam, 257-274.

Fatah, D. A. (2011). Perkembangan Obligasi Syariah (Sukuk) di Indonesia: Analisis Peluang dan Tantangan. Al-'Adalah, 34-46.

Fathurahman, H., \& Fitriati, R. (2013). Comparative Analysis of Return on Sukuk and Conventional Bonds. American Journal of Economics , 159-163.

Hastuti, E. S. (2017). Sukuk Tabungan: Investasi Syariah Pendorong Pembangunan Ekonomi Inklusif. Jurispundence , 114-122.

Hesse, H. A. (2008). Trens and Challenges in Islamic Finance. World Economy, 1-12.

Iskandar, A. (2014). Pengaruh Penerbitan Sukuk Negara Sebagai Pembiayaan Defisit Fiskal dan Kondisi Ekonomi Makro Terhadap Perkembangan Perbankan Syariah di Indonesia. Journal of Info Artha Sekolah Tinggi Akuntansi Negara , 1-21.

Jakarsih, M., \& Rusyidiana, S. A. (2009). Perkembangan Pasar Sukuk: Perbandingan Indonesia, Malaysia, dan Dunia. Jurnal Bisnis dan Ekonomi , 1-18.

Kusuma, H. (2020, Juli 11). Daya Saing Infrastruktur RI Masih Tertinggal Jauh dari Negara Lain. Retrieved Desember 9, 2020, from detikfinance: https://finance.detik.com/infrastruktur/d-5089444/daya-saing-infrastruktur-ri-masihtertinggal-jauh-dari-negara-lain

Lahsasna, A., \& Lin, L. S. (2012). Issues in Islamic Capital Markets: Islamic Bond/ Sukuk. $d$ INTERNATIONAL CONFERENCE ON BUSINESS AND ECONOMIC RESEARCH (pp. 495-511). Bandung: Indonesia.

Latifah, S. (2020). Peran Sukuk Surat Berharga Syariah (SBSN) dalam Pertumbuhan Pembangunan Ekonomi Indonesia. Jurnal Ilmiah Ekonomi Islam , 421-427.

Mitsaliyandito, R. Q., Arundia, T., \& Kasri, R. A. (2017). Impact of sukuk market development on Indonesian Economic Growth. International Journal of Applied Business and Economic Research, 1-13.

Moeloeg, L. J. (2007). Metodologi Penelitian Kualitatif. Bandung: PT Remaja Rosdakarya Offset. 
Mohamad, S., Saripudin, K. N., Razif, N. F., Abdullah, L. H., \& Rahman, N. A. (2012). Case Study on Sukuk Musharakah Issued in Malaysia. Middle-Eaast Journal of Scientific Research, 168-175.

Mosaid, F. E., \& Boutti, R. (2014). Sukuk and Bond Performance in Malaysia. International Journal Economics and Finance, 226-234.

Nasrullah, A. (2015). Studi Surat Berharga Negara: Analisis Komparatif SukukNegara dengan Obligasi Negara dalam pembiayaan Defisit APBN. Jurnal Lentera: Kajian Keagamaan, Keilmuan, dan Teknologi , 197-216.

Peristiwo, H. (2016). Analisis Minat Investor di Kota Serang Terhadap Investasi Syariah pada Pasar Modal Syariah. Islamiconomic, 37-52.

Ramadayanti, R. S., Mainata, D., \& Pratiwi, A. (2017). Peran Sukuk Negara dalam Pembiayaan Infrastruktur. Jurnal Ekonomi dan Bisnis Islam Al-Tijary, 155-176.

Sunarsih, S. (2008). Potensi Obligasi Syariah Sebagai Sumber Pendanaan Jangka Menengah dan Panjang bagi Perusahaan di Indonesia. Asy-Syariah: Jurnal Ilmu Syariah dan Hukum , 55-83.

Umam, K. (2013). Manajemen Perbankan Syariah. Bandung: Pustaka Setia. 